\title{
ANALYSIS OF THE ROLE OF CENTRAL CHOLINOREACTIVITY IN EXPERIMENTAL TRAUMATIC BRAIN INJURY
}

\author{
Sergey Khudoley ${ }^{1}$ \\ 1"MedicoMente" Medical Center for Modern Addictology, st. "Kalina”, ss. Gnedinskiy, Borispolsky district, Kiev region, Ukraine \\ khudoley.sergey@gmail.com \\ ORCID: http://orcid.org/0000-0001-9710-5105
}

ARTICLE INFO

A B S T R A C T

Article history:

Received date 23.09.2020

Accepted date 26.10 .2020

Published date 30.10 .2020

The aim of the research. To study effects of activation and inhibition of the central cholinergic systems (CCS) in traumatic brain injury (TBI).

Section:

Practical medicine

Studied problem. To investigate the influence of the reactivity of the central cholinergic systems on the course of the acute period of traumatic brain injury, in an acute experiment on laboratory animals in vivo.

DOI

The main scientific results. It was found that in the acute period of TBI (the first three

$10.21303 / 2313-8416.2020 .001456$ days), both activation and blockade of CCS led to a decrease in mortality, which was statistically confirmed only for their activation. The control group was characterized by the progression of neurological deficit, which was realized due to motor disorders and reflex

KEYWORDS

central cholinergic systems experimental traumatic brain injury neurological deficit sphere. Upon activation of the CCS, the degree of neurological deficit was significantly less than in other groups, but, nevertheless, it increased from 48 hours after the injury, as regards behavioral and consciousness disorders. Inhibition of cholinergic systems led to a sharp increase in neurological deficit in all areas immediately after injury, to a greater extent due to reflex disorders. This, together with a high mortality rate, indicated a negative effect of the pharmacological shutdown of CCS in TBI.

The area of practical use of the research results. The obtained results will allow a deeper study of the influence of the central cholinergic systems on the course and descent of TBI. To develop effective methods of pharmacological correction in the treatment of patients in the acute period of TBI.

Innovative technological product: pathogenetically substantiated medical treatment of the acute period of traumatic brain injury, development of new methods of pharmacological neuroprotection for persons with a priori high risk of injury, development of effective options for reducing mortality and disability from TBI.

Scope of the innovative technological product. The important role of CCS in the realization of the response of the central nervous system to TBI was established, and the possibility of using pharmacological stimulation of the central nervous system with cholinomimetics of the central type of action was justified.

(C) The Author(s) 2020. This is an open access article under the CC BY license http://creativecommons.org/licenses/by/4.0).

\section{Introduction}

\section{1. The aim of the research} brain injury.

Determination of the effect of activation and blockade of CCS on the course of traumatic

\section{2. Problem description}

Today in the world one of the leading causes of death and disability among the working-age population of the earth is traumatic brain injury (TBI). Especially the situation has changed in the last 10-15 years [1, 2], the number of man-made disasters, natural disasters, acts of terrorism and military conflicts on earth has sharply increased, which is accompanied by a high degree of trauma, in the structure of which the damage to the skull and brain is more than $1 / 3$ of all injuries [2-4]. In different countries, traumatism in the structure of mortality follows cardiovascular and oncological diseases, but the economic and medico-social damage caused to society brings TBI to the first place. Every year, both the TBI itself and its long-term 
consequences cost the world economy about 400 billion US dollars, which is about $0.5 \%$ of the total gross world product [5].

In Ukraine, this indicator is $2-3$ times higher than in economically developed countries. These indicators have increased significantly since the end of 2014, which is directly related to the situation in the country, aggravated by the conflict and hostilities in the east of Ukraine. According to the data published by the OSCE monitoring mission [6], traumatization as a consequence of explosive impacts and injuries has sharply increased, while this indicator is high both among military personnel and among the civilian population.

The sequence of events that occur after brain injury consists of necrosis, axonal damage, gliosis/microgliosis, apoptosis, demyelination and neuroregeneration [7]. The first acute period is of the greatest importance for the formation of an adequate response [8]. It is at this time that the main causal relationships are established, which determine the further development of the disease, its severity and outcomes, which gives reason to focus not only on the clinical, but also on the pathogenetic significance of this period [9].

In traumatic brain injury in the population of neurons there is a complex of interdependent extra- and intracellular processes triggered by tissue ischemia [10]. The latter serves as a trigger mechanism for events that ultimately lead to degeneration and death of neurons. The immediate cause of the primary phase is mechanical damage, which is irreversible, including cell destruction and vascular damage; manifested by brain contusion, intracranial hemorrhage, diffuse axonal damage [7]. A key role at this stage belongs to calpain (a family of cytosolic neutral $\mathrm{Ca}^{2+}-$ activated cysteine proteases), which triggers neurodegeneration and apoptosis [11]. The secondary phase includes cascades of neurochemical and neurometabolic events, apoptosis of neurons in isolated areas of the brain; mediated by caspases and manifested by intracranial hypertension, edema and hypoxia of the brain $[11,12]$.

One of the main mediators of the CNS is acetylcholine, which mediates its action through muscarinic $(\mathrm{M}-)$ and nicotinic $(\mathrm{N}-)$ receptors, which are widely expressed in the brain [13, 14]. The former are associated with G-proteins and mobilize intracellular calcium or reduce the content of cyclic adenosine monophosphate. The second are $\mathrm{Na}^{+}-, \mathrm{K}^{+}-$and, sometimes, $\mathrm{Ca}^{2+}$ ion channels. The latter are of great importance in the implementation of neuroplasticity, cognitive processes, neuroprotection $[15,16]$. From the very beginning of the damaging effect of trauma, the activity of central cholinergic systems (CCS) and the release of acetylcholine decreases, the expression of cholinergic receptors decreases and acetylcholinesterase is activated [17, 18].

\section{3. Suggested solution to the problem}

The introduction of the cholinomimetic cytidine-5'-choline diphosphate in TBI improves the cognitive abilities in the experiment and the release of acetylcholine [19]. The neuroprotective effect of the drug is associated with the induction of activation of nicotinic $\alpha 7$ receptors [20]. On the other hand, studies using the acetylcholinesterase blocker donepezil have had mixed results. Thus, it has been shown that it enhances neurogenesis and improves cognitive function after TBI [21], which has not been confirmed in other works [22].

The aim of the study was to analyze the effect of changes in central cholinoreactivity on mortality and neurological deficit in the acute period of experimental traumatic brain injury.

\section{Material and methods}

The study was performed on white male Wistar rats weighing 200-215 g, aged six months $(\mathrm{n}=101)$. The conditions of the Declaration of Helsinki (General Assembly of the World Medical Association, 2008), norms and principles of the European Convention for the Protection of Vertebrate Animals used for research and other scientific purposes were strictly observed.

\section{1. Experimental procedures}

Cholinergic and cholinolytic effects on the CNS were simulated by the introduction of central cholinomimetics and cholinoblockers. For this we used certified pharmaceuticals: choline alfoscerate ("Gliatilin", "Pharmacor PRODUCTION", RF; central cholinomimetic, which enhances the transmission of impulses in cholinergic neurons, improves cell neuroplasticity, receptor function and synaptic acid transmission) and (“Akineton”, "Laboratorio PHARMACEUTICO SIT, srl”, Italy; anticholiner- 
gic drug of central action, which reduces the activity of cholinergic neurons in the CNS). To achieve an effective concentration of substances in the brain structures and maximum cholinomodulatory effect on the CNS, as well as taking into account the periods of accumulation of active substance and half-life, clearance of excretion, allowable daily dose and based on the average weight of the animal, such a scheme was administered. For 24, 12, 6 and 1 hour before modelling TBI we intraperitoneally administered: in the 1st group Ringer's solution $0.5 \mathrm{ml}$ (control); in the 2nd group - Ringer's solution $0.47 \mathrm{ml}$ and $0.03 \mathrm{ml}$ of choline alfoscerate (the dose was $6 \mathrm{mg} / \mathrm{kg}$ ); and in the 3rd group - Ringer's solution $0.44 \mathrm{ml}$ and $0.06 \mathrm{ml}$ of biperiden hydrochloride (the dose was $0.6 \mathrm{mg} / \mathrm{kg}$ ).

TBI was applied by the standard method when the metal load fell freely on the fixed head of the animal [23]. The load was a round metal rod weighing $50 \mathrm{~g}$, which moved freely along a metal tube $65 \mathrm{~cm}$ long, fixed strictly perpendicular to the metal frame. Using superficial ether anesthesia, the animal's head was fixed under a vertically arranged metal tube so that the opening of the tube was along the sagittal suture and symmetrically $5 \mathrm{~mm}$ forward of the intraarticular line. The load fell freely along the tube and struck a single blow on the skull. According to our preliminary data, this model made it possible to obtain a clearly standardized moderate TBI [23]. Pathological examination showed that the animals were simulated closed traumatic brain injury in the presence of subcutaneous hematoma, without displacement of the brain and with crushing of the temporal and parietal cortex in the area of impact - the base of the frontal and temporal lobes. Numerous diffuse small hemorrhages were observed in the substance of the brain.

To assess the severity of TBI, a 100-point scale for determining neurological deficit was chosen [23], which was used for a separate assessment (in points) of the level of consciousness 0-20 points; state of the reflex sphere, which included the width and reaction of the pupils to light, corneal reflex, hearing, muscle tone of the torso and extremities - 0-28 points; breathing 0-12 points; movement and locomotor functions - 0-25 points, as well as some behavioural reactions with the ability to perform elementary functions $-0-15$ points.

The obtained results were subjected to statistical processing using a package of licensed programs for applied statistics SPSS 11.0, MedStat, MedCalc (MedCalc SoftWare bvba, 1993-2013). Conducted a comparative and correlation analysis of data from intact, control and experimental groups. The following methods of parametric statistics are used in the work: conducted an analysis of normality (criteria $\chi$-square and Kolmogorov-Smirnov). The following statistical indicators were calculated: mean value, statistically significant differences, mean and standard deviations, standard error. In order to assess the calculations of the average sample population used a parametric criterion of difference - t-Student, which is used to assess the dependent and independent data.

\section{Results}

In animals during the first three days after TBI mortality in the groups differed significantly, that is shown in Table 1. No mortality was determined when CCS (1st group) was activated, whereas CCS blockade was accompanied by a mortality of $12.5 \%$, which was twice less than in the control $(25.0 \%)$. The difference in mortality between the control and the group with CCS blockade was not statistically significant $(\mathrm{p}=0.204)$.

Table 1

Analysis of mortality of experimental animals ( $\mathrm{n}=32$ in each group)

\begin{tabular}{|c|c|c|c|}
\hline \multirow{2}{*}{ Group } & \multicolumn{2}{|c|}{ Dead animals } & \multirow{2}{*}{$\mathbf{p}$} \\
\hline & $\mathbf{n}$ & $\%$ & \\
\hline 1st (control) & 8 & 25.0 & \\
\hline 2nd (CCS - activation) & 0 & 0.0 & 0.010 \\
\hline 3rd (CCS - blockade) & 4 & 12.5 & \\
\hline
\end{tabular}

Note: $p$ - statistical significance (accepted at $P<0,05)$ by Pearson's $\chi^{2}$ criterion with Yates correction; paired intergroup comparisons: 1 st vs 2 nd $-p=0.003$; 1 st vs $3 r d: p=0.204 ; 2 n d v s 3 r d-p=0.040$

Thus, both activation and blockade of central cholinergic systems led to a decrease in mortality, which was statistically confirmed only for their activation $(p=0.003)$. 
The degree of neurological deficit in the group of intact animals remained unchanged throughout the experiment and amounted to $5.4 \pm 0.76$ points, which reflected, in our opinion, in the physiological characteristics of rodents. Thus, in some animals there were minor violations of the reflex sphere (from 4 to 8 points), which were reflected in the weakening of the pupillary response to light and the corneal reflex, spastic tone of the torso muscles and decreased pain response. This indicator was considered by us as a starting point in the following comparisons in the dynamics of the acute period of TBI.

3 hours after TBI, the neurological deficit in the 1st (control) group was $25.6 \pm 4.21$ points, which is 4.7 times higher than baseline in Table 2. In general, in animals of this group, the changes were associated with a change (darkening/stupor) in the level of consciousness, impaired behavioural responses and decreased reflexes. In half of the animals, the tone of the body and limbs became spastic, atactic manifestations appeared during movements. Probably due to compensatory or stress-related mechanisms, the frequency of respiratory movements also increases. In the 2nd group (activation of CCS) no significant changes in neurological status were observed. The degree of neurological deficit varied insignificantly, and was $25 \%$ higher than baseline $(\mathrm{p}>0.05)$. Changes were observed exclusively in the reflex sphere: there was a decrease in response to sound stimuli and pain sensitivity. The maximum increase in neurological deficit was observed in group 3 (CCS suppression), the total score was 7.7 times higher than baseline $(\mathrm{p}<0.05)$. The level of consciousness in these animals was characterized as "darkening/stupor", was determined by a moderate or severe deficiency of the reflex sphere: reduction/absence of perception of light, sound and pain stimuli. There was a marked decrease in muscle tone of the body and limbs, the animals were lethargic, adynamic, did not respond to the actions of the experimenter. All rats in the group had bradypnea.

Table 2

Neurological deficit in the experimental groups (in points; $\mathrm{M} \pm \mathrm{m}$ )

\begin{tabular}{ccccc}
\hline \multirow{2}{*}{ Group } & \multicolumn{4}{c}{ Time after injury, hours } \\
\cline { 2 - 5 } & $\mathbf{3}$ & $\mathbf{2 4}$ & $\mathbf{4 8}$ & $\mathbf{7 2}$ \\
\hline 1st (control) & $25.6 \pm 4.2$ & $32.8 \pm 2.5$ & $42.3 \pm 2.2$ & $51.3 \pm 3.0$ \\
2nd (CCS - activation) & $6.8 \pm 0.6^{*}$ & $7.3 \pm 0.5^{*}$ & $12.5 \pm 1.3^{*}$ & $16.8 \pm 1.7^{*}$ \\
3rd (CCS - blockade) & $41.4 \pm 1.9^{*}$ & $46.1 \pm 1.3^{*}$ & $51.3 \pm 1.2^{*}$ & $52.9 \pm 1.1$ \\
Note: ${ }^{*}-p<0.05$ in comparison with the 1st group (control) & &
\end{tabular}

After 24 hours, the average score in the animals of the 1st group was $32.8 \pm 2.47$, mainly due to the increase in the deficit in the reflex and motor spheres. The indicators in the 2nd group remained practically unchanged, where in all animals the decrease in the reaction to the light stimulus was determined. Neurological deficit increased 9.5 times $(p<0.05)$ in the 3rd group, where all animals had no indicators of the reflex sphere, while maintaining a high spastic tone of the extremities. Other indicators remained at the level corresponding to 3 hours after TBI.

48 hours after the injury in the 1st group, the neurological deficit was almost 8 times higher than the initial values and amounted to $42.3 \pm 2.21$ points. At the same time, in $1 / 3$ of animals the neurological deficit continued to grow. In the 2 nd group by this time there was an increase in the degree of neurological deficit (2.3 times compared to the initial), which was statistically significant $(p<0.005)$. This was due to the appearance of motor disorders in $1 / 3$ of the animals. In group 3 , the total score continued to increase, and was 9.5 times higher than the original $(p<0.05)$. In addition to the previously described disorders, in $2 / 3$ of the animals there was dilation of the pupils, exophthalmos, complete lack of response to light stimuli.

72 hours after injury in animals of group 1, the degree of neurological deficit increased 9.5 times compared to baseline $(\mathrm{p}<0.05)$ and amounted to $51.3 \pm 2.98$ points. Conventionally, the animals were divided into two almost equal levels of subgroups: "moderate disorders" a steady decrease in neurological parameters, and "severe disorders" - their complete and persistent absence. In the 2nd group there was a significant positive dynamics against the 
background of increasing neurological changes: half of the animals had a persistent disturbance of consciousness, however, they adhered to purity, actively responded to the actions of the experimenter. In group 3, the degree of neurological deficit continued to increase (almost 10 times compared to baseline and amounted to $52.9 \pm 1.13$ points. All indicators of the reflex sphere were evaluated by the maximum score, the animals were in a state of stupor. Animals 3rd and, in part, the 1st group (with "pronounced disorders") stopped taking care of themselves, they remained brady and had apparently increased hypoxia, as evidenced by cyanosis of the extremities, there was a refusal of animals from food and water, body weight decreased by $15-25 \mathrm{~g}$ in comparison with the initial one.

In general, a comparison of the dynamics of the degree of neurological deficit in groups of animals showed a tendency to increase it in the acute period of TBI in Fig. 1. The greatest progression was characteristic of the 1st group, where the degree of neurological deficit doubled during the observation period $(\mathrm{p}<0.05)$. This reflected the progression of pathological changes in the brain in the acute period of TBI.

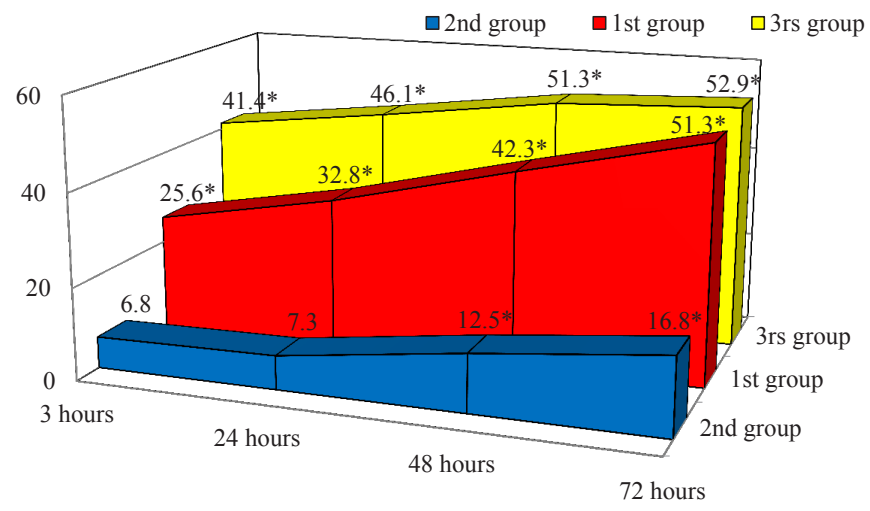

Fig. 1. Dynamics of the degree of neurological deficit in the acute period of TBI in groups of animals (points): ${ }^{*}-\mathrm{p}<0.05$ in comparison with initial indicators

In group 2, the degree of neurological deficit was significantly lower than in other groups, but still statistically significantly increased from 48 hours after injury. Apparently, the initial activation of the central cholinergic systems prevented neurological disorders immediately after TBI. However, in the future the neurological deficit had a positive trend.

In the 3rd group, the indicators of the degree of neurological deficit also progressed 1.3 times $(\mathrm{P}<0.05)$ after 48 hours, compared with the level of 3 hours. This indicated that the initial inhibition of cholinergic systems immediately after injury led to a sharp increase in neurological deficit. This, together with high mortality, indicated a negative effect of pharmacological exclusion of brain cholinergic systems in TBI.

A detailed analysis of the dynamics of the degree of neurological deficit by areas showed some differences in the selected groups (Tables 3-5). In the 1st group in all areas there was a statistically significant increase in the score of neurological deficit in Table 3. The biggest changes concerned motor disorders and the reflex sphere. This indicated that in the basic model of TBI, coordination of movements and higher nervous activity were more damaged.

In group 2, against the background of activation of cholinergic systems of the brain, the total score, as already mentioned, was the lowest. However, from 24 hours after the injury there was an increase. It was found that these disorders were more related to disorders of behaviour, consciousness and reflexes in Table 4.

Although motor disorders appeared after 48 hours, they were minimal and mainly related to impaired coordination. Thus, it could be concluded that the previous activation of central cholinergic systems significantly reduced disorders in all neurological areas, especially - motor disorders.

In group 3, against the background of blockade of the central cholinergic systems, 3 hours after TBI, the total score was maximum in groups in all neurological areas. The maximum changes concerned the reflex sphere in Table 5. 
Table 3

Indicators of neurological deficit (in points; $\mathrm{M} \pm \mathrm{m}$ ) in the 1st group (control)

\section{Indicator}

Conscious.

Reflexes

Breath

Movements

Behaviour
$5.42 \pm 0.42^{\text {\& }}$

$10.08 \pm 1.20^{\# \text { \&S }}$

$3.00 \pm 0.90^{\# \& \&}$

$2.92 \pm 0.97^{\text {s\& }}$

$4.17 \pm 1.11^{\text {s\& }}$
Time after injury, hours

24

$5.00 \pm 0.87^{\&}$

$13.42 \pm 0.97^{* \$ \&}$

$6.00 \pm 0.00 *$

$3.75 \pm 0.65^{\&}$

$4.58 \pm 0.97^{\text {se }}$
48

$5.83 \pm 0.83^{\&}$

$18.33 \pm 1.15^{\text {*\# }}$

$6.00 \pm 0.00$ *

$5.42 \pm 0.42 * \&$

$6.75 \pm 0.87$ *\#

\section{2}

$7.50 \pm 0.75^{* \# \$}$

$21.58 \pm 1.60$ *\#

$6.00 \pm 0.00 *$

$7.92 \pm 0.74 * \#$

$8.50 \pm 0.45^{* \#}$ p

0.027

$<0.001$

$<0.001$

$<0.001$

$<0.001$

Note: * the difference from the indicator at the time of 3 hours is statistically significant, $p<0.05$; \# - the difference from the indicator at the time of 24 hours is statistically significant, $p<0.05 ; \$$ - the difference from the indicator at the time of 48 hours is statistically significant, $p<0.05 ; \&$ - the difference from the indicator at the time of 72 hours is statistically significant, $p<0.05$

Table 4

Indicators of neurological deficit (in points; $\mathrm{M} \pm \mathrm{m}$ ) in the 2nd group (activation of CCS)

\begin{tabular}{|c|c|c|c|c|c|}
\hline \multirow{2}{*}{ Indicator } & \multicolumn{4}{|c|}{ Time after injury, hours } & \multirow{2}{*}{$\mathbf{p}$} \\
\hline & 3 & 24 & 48 & 72 & \\
\hline Conscious. & $0.00 \pm 0.00^{\&}$ & $0.00 \pm 0.00^{\&}$ & $0.94 \pm 0.50^{\&}$ & $2.50 \pm 0.65^{\text {*\#s }}$ & $<0.001$ \\
\hline Reflexes & $6.75 \pm 0.54^{\&}$ & $7.50 \pm 0.44^{\&}$ & $7.88 \pm 0.35^{\&}$ & $9.19 \pm 0.56^{\text {*\#\$ }}$ & 0.005 \\
\hline Breath & $0.00 \pm 0.00$ & $0.00 \pm 0.00$ & $0.00 \pm 0.00$ & $0.00 \pm 0.00$ & $>0.999$ \\
\hline Movements & $0.00 \pm 0.0^{\text {s\& }}$ & $0.00 \pm 0.00^{\mathrm{s} \&}$ & $1.88 \pm 0.63^{* \#}$ & $1.88 \pm 0.63^{* \#}$ & $<0.001$ \\
\hline Behavior & $0.00 \pm 0.00^{\$ \&}$ & $0.00 \pm 0.00^{\mathrm{s} \&}$ & $1.81 \pm 0.68^{* \# \&}$ & $3.19 \pm 0.69$ *\#\$ & $<0.001$ \\
\hline
\end{tabular}

Note: * - the difference from the indicator at the time of 3 hours is statistically significant, $p<0.05$; \# - the difference from the indicator at the time of 24 hours is statistically significant, $p<0.05 ; \$$ - the difference from the indicator at the time of 48 hours is statistically significant, $p<0.05 ; \&$ - the difference from the indicator at the time of 72 hours is statistically significant, $p<0.05$

Table 5

Indicators of neurological deficit (in points; $\mathrm{M} \pm \mathrm{m}$ ) in the 3rd group (blockade of CCS)

\begin{tabular}{|c|c|c|c|c|c|}
\hline \multirow{2}{*}{ Indicator } & \multicolumn{4}{|c|}{ Time after injury, hours } & \multirow{2}{*}{$\mathbf{p}$} \\
\hline & 3 & 24 & 48 & 72 & \\
\hline Conscious. & $6.07 \pm 0.57^{\&}$ & $6.43 \pm 0.63^{\&}$ & $7.14 \pm 0.69$ & $7.86 \pm 0.69^{* \#}$ & 0.010 \\
\hline Reflexes & $18.79 \pm 1.19^{\text {s\& }}$ & $22.00 \pm 0.58^{\mathrm{s} \&}$ & $25.93 \pm 0.60^{* \#}$ & $26.50 \pm 0.36^{* \#}$ & $<0.001$ \\
\hline Breath & $6.00 \pm 0.00$ & $6.00 \pm 0.00$ & $6.00 \pm 0.00$ & $6.00 \pm 0.00$ & $>0.999$ \\
\hline Movements & $5.00 \pm 0.00$ & $5.00 \pm 0.00$ & $5.00 \pm 0.00$ & $5.36 \pm 0.36$ & 0.403 \\
\hline Behaviour & $5.93 \pm 0.57^{\$ \&}$ & $6.64 \pm 0.36$ & $7.21 \pm 0.21^{*}$ & $7.21 \pm 0.21^{*}$ & 0.018 \\
\hline
\end{tabular}

Note: * the difference from the indicator at the time of 3 hours is statistically significant, $p<0.05$; \# - the difference from the indicator at the time of 24 hours is statistically significant, $p<0.05 ; \$$ - the difference from the indicator at the time of 48 hours is statistically significant, $p<0.05 ; \&$ - the difference from the indicator at the time of 72 hours is statistically significant, $p<0.05$

The average score of reflex disorders in the 3rd group in all terms significantly exceeded that in the 1st and 2nd groups in Fig. 2. This result showed that the blockade of the central cholinergic systems worsens primarily the reflex sphere, and, consequently, the subtle mechanisms of conjugation of the various departments of the CNS. This fact indicates the importance of activating the cholinergic systems of the brain in TBI for the implementation of complex reflex processes of nervous regulation. 


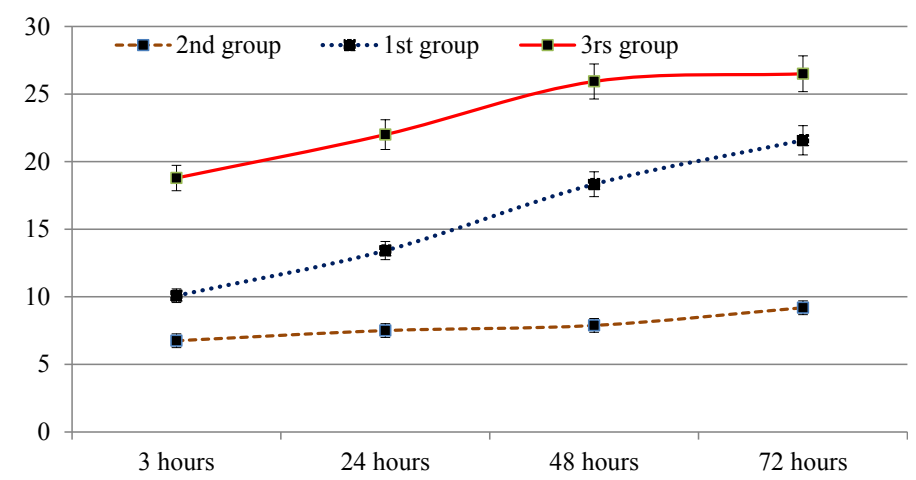

Fig. 2. Dynamics of reflex sphere disorders by groups (in points). The vertical axis is the score of neurological deficit. See statistical differences in Tables 3-4

\section{Discussion}

Regarding the comparison of motor disorders, it can be noted that the activation of cholinergic systems of the brain generally blocks such disorders, while in other groups they have a significant degree of severity. At the same time, if in the control group such violations systematically increase, then at blockade immediately after an injury reach rather high degree and then remain stable.

In the plan of negotiation of certain results, it is necessary to mean that the central holinoreceptors are in the foldable large-capacity bottles, as all the structural elements for the adaptation of the chemical signal, trigger the local alleviation of the concentration of acetylcholine allosteric machines [24]. Holinoreceptors are a superfamily of pentameric ligand-controlled channels, including receptor 5-hydroxytryptamin, able to inhibit anion-selective $\gamma$-aminobutyric acid type A (GABA-AR), glutamate [23]. At the same time, the activity of cholinoceptors is allosterically modulated by membrane lipids, fatty acids, steroids, instead of those in the brain tissue in TBI, it grows rapidly $[8,9,25,26]$.

Also, of the folding structure of holinoreceptors and of the modular flowing into the neurochemical systems is a factor of the primary post-traumatic disorder, which can be explained by the fact that there is a reason for the diagnosis.

As one of the main reasons of TBI, there is a particular significance of a wider spread of cholinoreceptors in the central nervous system, which is indicated for the hipocampus, tonsils, hypothalamus, frontal measles and mediodorsal nucleus of the thalamus [27]. The state-of-the-art and chronic systemic introduction of nicotine and other analogues in the structure significantly increased the work memory in the labyrinth and slowed down amnestic effects of the antagonist of NMDA-glutamate receptors in the dygozocylpirin [27]. Thus, we have seen a decrease in mortality and neurological deficiency in patients with TBI on the basis of post-mortem administration of an alfoscerate to explain the important role of CHS in the implementation of adaptive reactions, to bring the pathogenic importance of this need for malnutrition.

The impairment of the central nervous system function, which is an inherited TBI, includes cholinergic mechanisms [28]. It has been shown that in the case of contusion traumas of measles to the brain, the capacity of cholinergic and glutamate NMDA receptors decreased, as well as the expression of calcium channels, especially in the case of alpha7-cholinoceptor type. The very temporomandibular penetration is associated with neurodegeneration and significant neurological deficiency due to TBI [28]. Deficiency of the expression of alpha7-cholinoreceptor in cognitive impairment in TBI, while nicotinic receptor agonists restore this deficiency and lead to significant cognitive improvement compared with the control group. Use of the allosteric modulator of alpha7-cholinoreceptors AVL-3288 increased cognitive functions, while working memory in the water labyrinth was getting worse, which preceded the atrophy of the hipocampus due to percussion of TBI. It allowed to stand up, to strengthen the cholinergic transmission for the development of positive allosteric modulation of alpha7-cholinoreceptors, which can be a new therapeutic method for reducing the damage to the nervous system in patients with TBI.

In addition, the specific activation of alpha7-cholinoreceptors reduces the penetration of the hematoencephalic barrier in the course of experimental TBI. Such an effect is a blocker of acetyl- 
cholinesterase galanthamine, which, in addition, is allosterically susceptible to signal transmission in N-cholinoreceptors and changes in the degeneration of GABA-ergic neurons in hypochondriacal cells. In our opinion, the positive effect of cholin alfoscerate can be explained by the very modulatory infusion of alpha7-cholinoreceptors, which outstrips the calcification mechanisms of the nerve tissue, as in TBI, which in primary trauma are primary and irreversible due to calpain activation, leading to apoptosis and neurodegeneration.

Thus, the study showed a significant effect of activation/inhibition of central cholinergic systems on the acute period of TBI. The positive results obtained using the central cholinomimetic choline alfoscerate, allow us to continue research to study the mechanisms of the effect.

Study limitations. Given the increase in the neurological deficit in the dynamics of observation during the activation of CCS, it is advisable to continue research on the use of drugs after the application of TBI.

Prospects for further research. The obtained results showed the prospects of using central cholinomimetics for the correction of neurological disorders in the acute period of trauma. It is necessary to find out the mechanisms of such influence in the future.

\section{Conclusions}

1. In the acute period of TBI, both activation and blockade of CCS leads to a decrease in mortality, which was statistically confirmed only for their activation.

2. Comparison of the degree of neurological deficit showed a clear tendency to increase against the background of TBI. The greatest progression was characteristic of the control group, where the degree of neurological deficit doubled during the observation, which was realized due to motor disorders and reflex sphere.

3. With the activation of central cholinergic systems, the degree of neurological deficit was significantly lower than in other groups, but still increased from 48 hours after injury, related to behavioural and conscious disorders.

4. Inhibition of cholinergic systems immediately after injury led to a sharp increase in neurological deficits in all areas, but, more, due to reflex disorders. This, together with high mortality, indicated a negative effect of pharmacological exclusion of cholinergic systems of the brain on the background of TBI.

\section{Conflicts of interest}

The authors declare that they have no conflicts of interest.

\section{References}

[1] Dewan, M. C., Rattani, A., Gupta, S., Baticulon, R. E., Hung, Y.-C., Punchak, M. Et. al. (2019). Estimating the global incidence of traumatic brain injury. Journal of Neurosurgery, 130 (4), 1080-1097. doi: http://doi.org/10.3171/2017.10.jns17352

[2] James, S. L., Theadom, A., Ellenbogen, R. G., Bannick, M. S., Montjoy-Venning, W., Lucchesi, L. R. et. al. (2019). Global, regional, and national burden of traumatic brain injury and spinal cord injury, 1990-2016: a systematic analysis for the Global Burden of Disease Study 2016. The Lancet Neurology, 18 (1), 56-87. doi: http://doi.org/10.1016/s1474-4422(18)30415-0

[3] Khellaf, A., Khan, D. Z., Helmy, A. (2019). Recent advances in traumatic brain injury. Journal of Neurology, 266 (11), $2878-$ 2889. doi: http://doi.org/10.1007/s00415-019-09541-4

[4] Laccarino, C., Carretta, A., Nicolosi, F., Morselli, C. (2018). Epidemiology of severe traumatic brain injury. Journal of Neurosurgical Science, 62 (5), 535-541. doi: http://doi.org/10.23736/S0390-5616.18.04532-0

[5] Ovsyannikov, D. M., Chekhonatsky, A. A., Kolesov, V. N., Bubashvili, A. I. (2012). Social and epidemiological aspects of craniocerebral trauma (review). Saratov journal of medical scientific research, 8 (3), 777-785.

[6] Findings on Formerly State-Financed Institutions in the Donetsk and Luhansk Regions (2015). Organization for Security and Co-operation in Europe. OSCE. Thematic report, 17. Available at: https://www.osce.org/ukraine-smm/148326?download $=$ true

[7] Abou-El-Hassan, H., Dia, B., Choucair, K., Eid, S. A., Najdi, F., Baki, L. et. al. (2017). Traumatic brain injury, diabetic neuropathy and altered-psychiatric health: The fateful triangle. Medical Hypotheses, 108, 69-80. doi: http://doi.org/10.1016/ j.mehy.2017.08.008

[8] Elskii, V. N., Kardash, A. M., Gorodnik, G. A.; Chernii, V. I. (Ed.) (2004). Patofiziologiia, diagnostika i intensivnaia terapiia tiazheloi cherepno-mozgovoi travmy. Donetsk: Novii mir, 200. 
[9] Ziablitsev, S. V., Elskii, V. M. (2020). Sindromy travmaticheskoi bolezni pri cherepno-mozgovoi travme. Kramatorsk: Kashtan, 350.

[10] Laurer, H., McIntosh, T. (2001). Pharmacologic Therapy In Traumatic Brain Injury: Update On Experimental Treatment Strategies. Current Pharmaceutical Design, 7 (15), 1505-1516. doi: http://doi.org/10.2174/1381612013397285

[11] Nokkari, A., Abou-El-Hassan, H., Mechref, Y., Mondello, S., Kindy, M. S., Jaffa, A. A., Kobeissy, F. (2018). Implication of the Kallikrein-Kinin system in neurological disorders: Quest for potential biomarkers and mechanisms. Progress in Neurobiology, 165-167, 26-50. doi: http://doi.org/10.1016/j.pneurobio.2018.01.003

[12] Bortolotti, P., Faure, E., Kipnis, E. (2018). Inflammasomes in Tissue Damages and Immune Disorders After Trauma. Frontiers in Immunology, 9. doi: http://doi.org/10.3389/fimmu.2018.01900

[13] Zhao, J., Hylin, M. J., Kobori, N., Hood, K. N., Moore, A. N., Dash, P. K. (2018). Post-Injury Administration of Galantamine Reduces Traumatic Brain Injury Pathology and Improves Outcome. Journal of Neurotrauma, 35 (2), 362-374. doi: http:// doi.org/10.1089/neu.2017.5102

[14] Belluardo, N., Mudo, G., Blum, M., Amato, G., Fuxe, K. (2000). Neurotrophic effects of central nicotinic receptor activation. Advances in Research on Neurodegeneration, 227-245. doi: http://doi.org/10.1007/978-3-7091-6301-6_15

[15] Mudo, G., Belluardo, N., Fuxe, K. (2006). Nicotinic receptor agonists as neuroprotective/neurotrophic drugs. Progress in molecular mechanisms. Journal of Neural Transmission, 114 (1), 135-147. doi: http://doi.org/10.1007/s00702-006-0561-z

[16] Kalappa, B. I., Sun, F., Johnson, S. R., Jin, K., Uteshev, V. V. (2013). A positive allosteric modulator of $\alpha 7$ nAChRs augments neuroprotective effects of endogenous nicotinic agonists in cerebral ischaemia. British Journal of Pharmacology, 169 (8), 1862-1878. doi: http://doi.org/10.1111/bph.12247

[17] Gorman, L. K., Fu, K., Hovda, D. A., Murray, M., Traystman, R. J. (1996). Effects of Traumatic Brain Injury on the Cholinergic System in the Rat. Journal of Neurotrauma, 13 (8), 457-463. doi: http://doi.org/10.1089/neu.1996.13.457

[18] Shin, S. S., Dixon, C. E. (2015). Alterations in Cholinergic Pathways and Therapeutic Strategies Targeting Cholinergic System after Traumatic Brain Injury. Journal of Neurotrauma, 32 (19), 1429-1440. doi: http://doi.org/10.1089/neu.2014.3445

[19] Dixon, C. E., Ma, X., Marion, D. W. (1997). Effects of CDP-Choline Treatment on Neurobehavioral Deficits after TBI and on Hippocampal and Neocortical Acetlycholine Release. Journal of Neurotrauma, 14 (3), 161-169. doi: http://doi.org/10.1089/ neu.1997.14.161

[20] Jonnala, R. R., Buccafusco, J. J. (2001). Relationship between the increased cell surface ?7 nicotinic receptor expression and neuroprotection induced by several nicotinic receptor agonists. Journal of Neuroscience Research, 66 (4), 565-572. doi: http:// doi.org/10.1002/jnr.10022

[21] Yu, T.-S., Kim, A., Kernie, S. G. (2015). Donepezil Rescues Spatial Learning and Memory Deficits following Traumatic Brain Injury Independent of Its Effects on Neurogenesis. Plos One, 10 (2), e0118793. doi: http://doi.org/10.1371/journal.pone.0118793

[22] Shaw, K. E., Bondi, C. O., Light, S. H., Massimino, L. A., McAloon, R. L., Monaco, C. M., Kline, A. E. (2013). Donepezil Is Ineffective in Promoting Motor and Cognitive Benefits after Controlled Cortical Impact Injury in Male Rats. Journal of Neurotrauma, 30 (7), 557-564. doi: http://doi.org/10.1089/neu.2012.2782

[23] Elskii, V. N., Ziablitsev, S. V. (2008). Modelirovanie cherepno-mozgovoi travmy. Donetsk: Novii Svet, 140.

[24] Changeux, J.-P. (2018). The nicotinic acetylcholine receptor: a typical “allosteric machine.” Philosophical Transactions of the Royal Society B: Biological Sciences, 373 (1749), 20170174. doi: http://doi.org/10.1098/rstb.2017.0174

[25] Abou-El-Hassan, H., Dia, B., Choucair, K., Eid, S. A., Najdi, F., Baki, L. et. al. (2017). Traumatic brain injury, diabetic neuropathy and altered-psychiatric health: The fateful triangle. Medical Hypotheses, 108, 69-80. doi: http://doi.org/10.1016/ j.mehy.2017.08.008

[26] Laurer, H., McIntosh, T. (2001). Pharmacologic Therapy In Traumatic Brain Injury: Update On Experimental Treatment Strategies. Current Pharmaceutical Design, 7 (15), 1505-1516. doi: http://doi.org/10.2174/1381612013397285

[27] Levin, E. D. (2013). Complex relationships of nicotinic receptor actions and cognitive functions. Biochemical Pharmacology, 86 (8), 1145-1152. doi: http://doi.org/10.1016/j.bcp.2013.07.021

[28] Verbois, S. L., Sullivan, P. G., Scheff, S. W., Pauly, J. R. (2000). Traumatic Brain Injury Reduces Hippocampal $\alpha 7$ Nicotinic Cholinergic Receptor Binding. Journal of Neurotrauma, 17 (11), 1001-1011. doi: http://doi.org/10.1089/neu.2000.17.1001 